\title{
Factors Affecting the Business Performance of Micro and Smal Enterprises: In Case of Hossana Town, Hadiya Zone
}

\author{
Tagesse Abebe Sugebo \\ Commercial Bank of Ethiopia; Bobico Branch, Hossana
}

\begin{abstract}
The micro and small enterprises has special importance in the economy that it is responsible for the major contribution of employment and income generation. However, their contribution is very low since the growth of MSEs is affected by a number of factors. Therefore, this study is intended to fill this gap by analyzing factors affecting the business performance of MSEs in Hadiya Zone, Hosanna town. The study mainly deployed explanatory research design with implementation of both quantitative and qualitative research approaches. Out of 287 MSEs, 167samples were selected using a stratified proportional random sampling technique, from which the required data were generated and analyzed through employing inferential analyses method. Pearson Correlation Coefficient and multiple linear regressions model were applied for inferential analyses. The findings indicate that; access to market, finance, working premises, management skill, technology, infrastructure and entrepreneur skill influence positively and significantly the business performance of MSEs with beta value $0.420,0.203,0.157,0.156$, $0.125,0.110$ and 0.107 respectively in the study area. To conclude the study results; access to market, finance and working premises were largely influenced factors of MSEs success. Based on the research findings the government has recommended to establish a centrally managed marketing site that will equally give access to market; Banks and Micro finances institutions have responsibilities to improve access to finance through offering a better lending terms and conditions in collaboration with government in order to advance performance of MSEs in Hosanna Town.
\end{abstract}

Keywords: MSEs, Business Performance, Factors, Hosanna Town.

DOI: $10.7176 / \mathrm{EJBM} / 12-13-03$

Publication date:May $31^{\text {st }} 2020$

\section{Introduction}

In many developed countries, more than $90 \%$ of all enterprises are within the MSE sub-sector while $80 \%$ of the total industrial labor force in Japan, $50 \%$ in Germany and 46\% in USA [1]. The performances MSE contribute nearly 39\% of the country's national income [27]. In emerging Asian countries the percentage of MSEs from all enterprises of Hong Kong, Thailand, Philippines, Japan, Malaysia, Singapore, and Taiwan are 98.0, 99.7, 99.6, 98.9, 99.7, 97.7 and 96.1 respectively and their business performance and employment creation contribution to total employed population is $60.0,58.0,70.0,69.2,45.0,57.0$, and 68.8 respectively [34]. According to African Development Bank, [3] studies: The role of the private sector, including MSEs, as engine of business growth was illustrated by the postwar recovery in Austria and Germany and by the diverging paths of Central and East European and Baltic countries. Despite such vital roles of MSEs in building a competitive private sector and contributing significantly to economic growth, sales growth, capital growth, and job creation, MSEs are facing numerous challenges around the world in general and in developing countries in particular [27]. With increased urban population dynamics of Sub-Saharan Africa (SSA), the importance of MSEs performance is also growing [34].

In Ethiopia, according to the Government the Federal Democratic Republic of Ethiopia MSE Development Strategy [13], the definition of MSEs performance is as follows: Micro Enterprises are business enterprises found in all sectors of the Ethiopian economy with a paid-up capital (fixed assets) of not more than Birr 100,000; Small Enterprises are business enterprises with a paid-up capital of more than Birr 100,000 and less than Birr 1.5 million.

In similar fashion, in cities and towns of Ethiopia, MSEs and the informal sector are the main income generating activities and thus they have a significant contribution to local economic development and used as the basic means of survival [14].

However, in case of Ethiopia despite the enormous potential importance of the MSE sector to the national economy with regards to job creation, performance growth and the alleviation of poverty, many of the MSEs are incapable to realize their full potential due to the existence of different factors that hinder their business performance [22]. Performance of a MSEs is defined as a firm's ability to create action and acceptable results [29]. According to [4], the business performance of MSEs can be seen from satisfaction of owners/ managers on profit, turnover and business development. Furthermore, a business Performance is an interrelated set of financial and non-financial measures designed to provide managers with vital information about the current state of the business and its future prospects [7]. There exists are variety of business performance indicators or measurements which are broadly categorized as financial and non-financial performance measurements and there was several previous researchers studied and examined various business factors that influence/affect the business performance of 
enterprises.

[21]; identified Business information services, Access to finance, Availability of management experience, Access to infrastructure, Government Policy and regulations was considered as factors that impact the business performance. A study in Thailand considers the following as factors that influences business performance of SMEs: SMEs characteristic, management and know how, products and services, Customer and Market, the way of doing business and cooperation, resources and finance, Strategy, and external environment' [6]. A study from Algeria considers Legal and political framework, Access to external financing, Human resources capacities, Entrepreneur characteristics, Management capacities, Marketing skills, Technological capacities, and SMEs internal factors as a factor affecting business performance [5]. Another study from Romania determines the factors as Strategy, Information Technology, Structure, Leadership, Innovation and development, Employees, Corporate governance, quality, Performance measurement and External environment.

In Ethiopia, [32] evaluated the major factors include financial problems, lack of qualified employees, lack of financial records, marketing problems and lack of work premises, etc. Besides, environmental factors affect the business which includes social, economic, cultural, political, legal and technological factors. In addition there are also personal attitudes or internal factors that affect the performance of MSE which are related to the person's individual attitude, training and technological knowhow. Another study [1] considers 'Politico-legal factors, Working premises, Technological factors, Infrastructural factors, Marketing factors and financial factors as a factor for business performance.

In Hosanna, [15] was studied with the aim of factors affecting micro and small enterprises in accessing credit facilities. The result of the study revealed that age of operator, educational level, and possession of fixed asset, employment size, lending procedure and loan repayment period are significant factors that affect MSEs' access to credit. Another study from Hosanna, determines the challenges as access to finance, access to market, and infrastructure are realized as major factors for MSE working in Hosanna Town with title of factors affect the growth of micro and small enterprises [9].

In reality, literature on MSEs in Ethiopia especially in the area of study is scanty, most of the available studies were not conducted in line with performance aspects of micro enterprises; there is disparities among variables and conceptual dimensions. Therefore, this study is aimed to investigate factors affecting the business performance of MSEs in a holistic way by targeting and deeply investigating those operators engaged in textile and garment, food processing and metal and wood work activities in Hadiya Zone, Hosanna Town.

\section{Statement of the problem}

The importance of MSEs in contributing to job creation and economic development is now widely accepted in both developed and developing countries [13]. Although, there are various initiatives which have been undertaken by the Ethiopian government and non-governmental organization to promote MSEs development across the country, but yet their performance is still low in which MSEs owners gets low income from them and yet they still living under poor condition and therefore, the sector's contribution to economic growth in the country is still low due to the sector's growth is influenced by a numbers of factors.

The challenging factors for MSEs growth vary from sector to sector, place to place, and population to population. Furthermore, in research of [18], profitability is considered as measure of performance and he recommends to add some other variables to assess the performance of MSEs. Moreover, in the study of [17] some findings regarding some factors are different from previous study. Their study also recommends for further research in order to frame additional variables by further examining and identifying the factors for MSEs growth. Therefore, this study is intended to address these gaps by answering what is the relationship among the potential factors that influence the business performance of MSEs operating in Hadiya Zone, Hosanna Town?

\section{Research hypothesis}

In this study after reviewing multiple theoretical and empirical literatures that have been studied and researched in the area, the study developed seven hypothesis that were examined as the influential factors that affects the business performance to MSEs.

H1: There is association between working premise and business performance of MSE;

$\mathrm{H} 2$ : There is relationship between technology and the business performance of MSE;

H3: There is relationship between infrastructure and the business performance of MSE;

H4: There is association between marketing and the business performance of MSE;

H5: There is association between finance and the business performance of MSE;

H 6: There is relationship between management skill and the business performance of MSE;

H7: There is relationship between entrepreneurial skill and the business performance of MSE;

\section{REVIEW OF RELATED LITERATURE}

[31]; research was conducted with the intention of assessing the contribution of the MSE strategy to poverty 
reduction, job creation and business development in focal cities of Ethiopia namely Adama, Hawassa, Bahirdar and Mekelle,. The raised causes for this gloomy prospect of business were not growing (33\%), lack of finance $(13 \%)$, lack of market (11\%), and lack of working space (4\%).

[13]; reviewed the major constraints identified by various studies on MSEs in Ethiopia are associated with market and finance problems. The causes of market-related problems of MSEs engaged in metal and wood work are shortage or absence of marketing skills, poor quality of products, absence of marketing research, shortage of market information, shortage of selling places, and absence of sub-contracting.

[26]; has also identified and categorized the critical problems of MSEs into market related problems, which are caused by poor market linkage and poor promotional efforts. Institution-related problems including bureaucratic bottlenecks, weak institutional capacity, lack of awareness, failure to abide policies, regulations, rules, directives, absence of training to executives, and poor monitoring and follow-up; operator-related short coming slick developing dependency tradition, extravagant and wasting behavior, and lack of vision and commitment from the side of the operators; MSE-related challenges including lack of selling place, weak accounting and record keeping, lack of experience sharing, and lack of cooperation within and among the MSEs and finally, societyrelated problems such as its distorted attitude about the operators themselves and their products.

[30]; assessed the major determinants of access to finance by using semi structured questionnaire administered to 134 randomly selected MSEs in Asella. They used Binary logistic regression model to identify major determinants of access to credit from formal financial institutions and test the hypotheses. The result of their study revealed that age of operator, educational level, and possession of fixed asset, employment size, lending procedure and loan repayment period are significant factors that affect MSEs' access to credit.

[18];research paper was aimed at investigating factors affecting the performance of MSEs with a special emphasizes on Textile \& Garment, Food Processing and Wood \& Metal work sectors in Yeka Sub-City, Addis Ababa. The empirical study elicit eight major independent variables which seem to affect performance of MSEs in Yeka sub-city which include: Inadequate finance, Lack of working premises, Marketing problem, Inadequate infrastructure, Poor management practices, Technological, Entrepreneurial and Political-legal factors. The findings further indicated that among the independent variables working premises, Marketing and Financial factors were the major factors that significantly affected performance.

[23]; Study is intended to fill the gap by exploring the challenges and prospects of the entrepreneurs in the small enterprise in general and specifically rate the challenges across each sector in Mekelle and Adigrat, Tigray Regional State of Ethiopia. His study selects 154 samples of the small enterprise by using a stratified proportional random sampling technique, from which the required data were generated and analyzed employing the descriptive and exploratory research design. Overall, his study result discloses a high failure rate of the small enterprises in the study sites and one can conclude that there is a lack of innovation from the side of entrepreneurs and a weak support from the government and other supporting institutions.

[20]; research described the relationship between performance and personal related factors and business related factors on MSEs in Bole sub city of Addis Ababa.In terms of the his study result, descriptive statistics shows higher performance for enterprises owned by individuals with better education level, prior management experience, marketing skill and planning and record keeping.

[2]; explained the influential business factors that affect the business performance of small and medium enterprises (SMEs) in Addis Ababa Nifas Silk Lafeto Sub City. The regression results showed that the eight hypothesized factors: financial, management, marketing, entrepreneurial, technology, politico-legal, infrastructural and working premises factors were found significantly affecting the business performance of SMEs operating in the sub city.

[4]; assessed the financial and operational determinant factors affecting MSE growth in Addis Ababa by measuring the key MSE's performance factors of some selected enterprises who are working in Addis Ketema sub City Administration. The study findings revealed that higher interest rate for loan, higher collateral requirement of loan providers, short period of loan repayment and limited institutions willing to provide loan for MSEs wellthought-out as great challenges.

[15]; assessed the major factors affecting access to credit by using proportionate stratified random sampling study selected 244 MSEs in hosanna towns. The result of the study revealed that age of operator, educational level, and possession of fixed asset, employment size, lending procedure and loan repayment period are significant factors that affect MSEs' access to credit.

[10], identified the factors affecting the performance of micro and small-scale enterprises in Wolkite town. His paper focused on determining the influence of factors like age, sex, family size, access to business information, access to, access to financial services and access to managerial skills on the performance of micro and small-scale enterprises. Especially, access to infrastructure and low-level education are the main factors that are affecting the performance of micro and small-scale enterprises in this town.

Finally, based upon the literature and empirical review as it is clearly indicted there are various factors that influence the performance of micro and small enterprises, which is undertaken by different researchers. But still 
in Ethiopia, the sector needs more researches to be done. The reason for this is most of the studies conducted several years ago and a lot must have been changed since then it is vital to undertake research in the sector because any good policy and strategies need to rely on timely information to promote micro and small scale enterprises, with the view to increase their contribution to poverty and unemployment reduction and economic growth. This study focus on describing factors influencing the performance of Micro and small enterprises in Hosanna Town.

\section{RESEARCH DESIGN AND METHODOLOGY Research Design}

According to [8]; an explanatory research design is used by investigators to explain and measure the degree of relationship between two or more variables. Therefore, the study was intended to employ an explanatory research design in order to explain the cause and effect relationship among variables that correlated to estimate the integrated influence of explanatory variables on performance.

\section{Method of Data Analysis}

This study used inferential statistics to analyze data that was collected. Correlation, ANOVA, SPSS version 20 and regression models were used to analyze data. Analysis of variance (ANOVA) is used to test the hypotheses stated in this study regarding the business performance of enterprises in relation to each of the independent variables (working premises, technology, infrastructural, marketing, financial, management and entrepreneurial) of the study. Statistical Package for Social Sciences (SPSS) was used as a tool for statistical analysis and the results and was presented in figures and tables. Moreover, linear regression analysis was used to test the statistical significance on the relationship that existed between the independent variables (working premises, technology, infrastructural, marketing, financial, management and entrepreneurial) factors on the (dependent variable) business performance of MSE.

\section{Model Specification}

In this study, multiple linear regression models were executed to achieve research objectives. The basic objective of using multiple linear regression analysis in this study was to make the research more effective in analyzing impacts of independent variables (working premises, technology, infrastructural, marketing, financial, management and entrepreneurial) factors on the (dependent variable) business performance of MSE). Moreover, according to [16], "Multiple linear regression analysis is one of the most widely used statistical methods for analyzing business performance data. The method is used to study the relation between the factors (independent variables) and the overall business performance of MSE (dependent variable).',

\section{Regression Functions}

The equation of regressions on this study is generally built around two sets of variables, namely dependent variable (business performance) and independent variables (working premises, technology, infrastructure, marketing, finance, management and entrepreneurial). The basic objective of using regression equation on this study is to make the study more effective at describing, understanding and predicting the stated variables; asit was defined by Gujarati, (1995). Based on the definition of Gujarati, (1995), the business performance was regretted on Selected Variables as stated below:

\section{Where:}

$$
\mathrm{Y}=\beta 0+\beta 1 \mathrm{X} 1+\beta 2 \mathrm{X} 2+\beta 3 \mathrm{X} 3+\beta 4 \mathrm{X} 4+\beta 5 \mathrm{X} 5+\beta 6 \mathrm{X} 6+\beta 7 \mathrm{X} 7+\mathrm{ue}
$$

$\mathrm{Y}$ is the response or dependent variable- business performance

$\mathrm{X} 1=$ working premises, $\mathrm{X} 2=$ technology, $\mathrm{X} 3=$ infrastructure, $\mathrm{X} 4=$ marketing, $\mathrm{X} 5=$ finance, $\mathrm{X} 6=$ management and $\mathrm{X} 7=$ entrepreneurial skills are the explanatory variables.

$\beta 0$ is the intercept term-constant which would be equal to the mean if all slope coefficients are 0 .

$\beta 1, \beta 2, \beta 3, \beta 4, \beta 5, \beta 6$, and $\beta 7$ are the coefficients associated with each independent variable which measures the change in the mean value of $Y$, per unit change in their respective independent variables.

Ue is error term. Ue can be described as;

$$
\mathrm{Ue}=\mathrm{Y}-\beta 0-\beta 1 \mathrm{X} 1+\beta 2 \mathrm{X} 2+\beta 3 \mathrm{X} 3+\beta 4 \mathrm{X} 4+\beta 5 \mathrm{X} 5+\beta 6 \mathrm{X} 6+\beta 7 \mathrm{X} 7
$$

\section{Result and discussion \\ Correlation Coefficient Matrix}

The findings indicate that financial, management, infrastructural, working premises, and entrepreneur factors have a strong and significantly positive association with business performance $(\mathrm{r}=0.781, \mathrm{p}<0.05 ; \mathrm{r}=0.753, \mathrm{p}<0.05 ; \mathrm{r}$ $=0.691, \mathrm{p}<0.05 ; \mathrm{r}=0.628, \mathrm{p}<0.05$; and $\mathrm{r}=0.611, \mathrm{p}<0.05)$ respectively. This implies that an increase in access to finance, infrastructure, working premises, and increase in management and entrepreneurial skill resulted in an increase in business performance of MSE in study area. See table 2 below about correlation matrix. 
Table 2 Pearson Correlations Matrix:

\begin{tabular}{|c|c|c|}
\hline Independent variables & Statistics & Dependent variables \\
\hline \multirow[t]{3}{*}{ Working premises factors } & Pearson Correlation $\AA$ & $.628^{* *}$ \\
\hline & Sig. (2-tailed) & .000 \\
\hline & $\mathrm{N}$ & 156 \\
\hline \multirow[t]{3}{*}{ Technology factors } & Pearson Correlation $\AA$ & $.333^{* *}$ \\
\hline & Sig. (2-tailed) & .000 \\
\hline & $\mathrm{N}$ & 156 \\
\hline \multirow[t]{3}{*}{ Infrastructure factors } & Pearson Correlation ${ }^{\circledR}$ & $.691^{* *}$ \\
\hline & Sig. (2-tailed) & .000 \\
\hline & $\mathrm{N}$ & 156 \\
\hline \multirow[t]{3}{*}{ Marketing factors } & Pearson Correlation $\AA$ & $.891^{* *}$ \\
\hline & Sig. (2-tailed) & .000 \\
\hline & $\mathrm{N}$ & 156 \\
\hline \multirow[t]{3}{*}{ Finance factors } & Pearson Correlation $\AA$ & $.781^{* *}$ \\
\hline & Sig. (2-tailed) & .000 \\
\hline & $\mathrm{N}$ & 156 \\
\hline \multirow[t]{3}{*}{ Management factors } & Pearson Correlation $\AA$ & $.753^{* *}$ \\
\hline & Sig. (2-tailed) & .000 \\
\hline & $\mathrm{N}$ & 156 \\
\hline \multirow[t]{3}{*}{ Entrepreneurial factors } & Pearson Correlation $\AA$ & $.611^{* *}$ \\
\hline & Sig. (2-tailed) & .000 \\
\hline & $\mathrm{N}$ & 156 \\
\hline
\end{tabular}

**. Correlation is significant at the 0.01 level (2-tailed).

Source: Own Survey result, 2019

\section{Regression/Correlation Analysis}

The multiple regression analysis is an analysis of association in which the effects of two or more independent variables on a single, interval scaled dependent variable reinvestigated simultaneously [35]. The results of this analysis indicate how well a set of variables is able to predict the dependent variable. Furthermore, it shows how much unique variance in the dependent variable is explained by each of independent variables [35]. Regression analysis is conducted to know by how much the independent variable explains the dependent variable. It is also used to understand by how much each independent variable (management factor, entrepreneurial factors, marketing factors, infrastructural factor, infrastructural, financial factor, technological factor,) explains the dependent variable(business performance of MSE).

Therefore, for the whole regression analysis of this study the adjusted $\mathrm{R}$ square were considered to provide a better estimation of the true population than the normal $\mathrm{R}$ square. The results of the regression analysis are as following. For the purposes of determining the extent to which the explanatory variables explain the variance in the explained variable, regression analysis was employed. See table 3 below about the regression summary model. Table 3. Model Summary

\begin{tabular}{lllll}
\hline Model & R & R square & Adjusted R Square & Std. Error of the Estimate \\
\hline $\mathbf{1}$ & $.953^{\mathrm{a}}$ & .909 & .904 & .06778 \\
\hline
\end{tabular}

a. Predictors: (Constant), ENF, TCF, MGF, INF, WPF, FNF, MRF.

b. Dependent Variable: business Performance of MSEs

Source: Own Survey result, 2019

The regression summary model result indicates that the co-efficient of determination (R) with a value of 0.953 . Therefore, $\mathrm{R}$ value reveals that there is a strong positive relationship among marketing, infrastructure, technological, finance, working premises, managerial \& entrepreneurial skill and business performance. This implies the higher $\mathrm{R}$ is, the more reliable a prediction will be. Moreover, the R-square value in the model summary tells the goodness of fit of the model. R-square value for this model is $\mathrm{R} 2=0.909$. These findings confirm that the observed change in performance attributed to the identified factors was $90.90 \%$ while the remaining $9.10 \%$ could be explained by other intervening factors. In other words, with the possible error of $9.10 \%$, the MSE's business performance is affected by the identified factors.

\section{Analysis of Variance (ANOVA)}

Analysis of variance (ANOVA) is used to test the hypotheses stated in this study regarding the business performance of enterprises in relation to each of the independent variables (working premises, technology, 
infrastructural, marketing, financial, management and entrepreneurial) of the study. See table 4 below about the analysis of variance was done to establish the significance of the regression model.

Table 4 Analysis of Variance

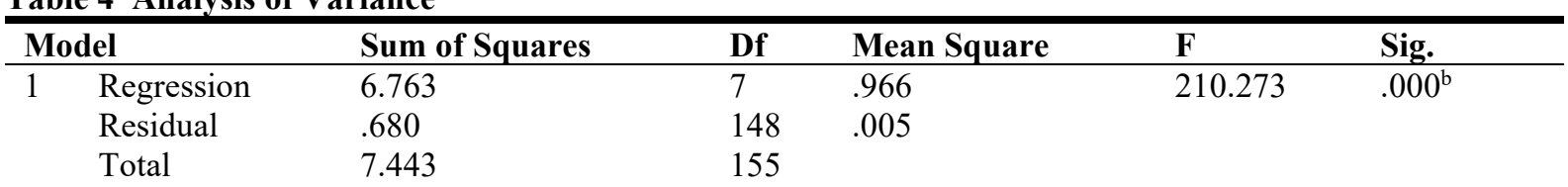

a. Dependent Variable: Business Performance of MSEs(Y)

b. Predictors: (Constant), Work premises(X1), Technological Factors(X2), Entrepreneurial Factors(X7), Managerial Factors(X6),Infrastructural Factors(X3), Financial Factors(X5), Marketing Factors(X4)

Source: Own survey result, 2019.

As seen in above table 4, total sum of squares (7.443) is equal to the sum of regressed or explained sum of squares (6.763) and unexplained by the regression or residual sum of squares (0.680). A study of these components total sum of squares of is known as the analysis of variance (ANOVA) from the regression perspective. Moreover, it is revealed the value of F-stat is 210.273 (a proportion of mean square of regression accounted by mean square of residual or unexplained regression) and it is significant at $p$ value of $0.00(p<0.05)$. This indicates that the overall model was reasonably fit and there was a statistically significant association between identified factors and business performance. Therefore, it can be concluded that explained factors have significant impact on business performance and the regression model used above is an appropriate prediction for explaining performance influencing factors in study area.

\section{Multiple Regression Analysis}

The study used a multiple regression analysis to achieve the objective of determining the effect of working premises, technology, infrastructure, market, finance, management \&entrepreneur skill on business performance of MSEs and test the study hypotheses, the combined independent variables (finance, management, entrepreneur, marketing, technology, working premises and infrastructure) were regressed on the dependent variable (business performance of MSEs). See Table 5 on the regression results.

Table 5 Regression results

\begin{tabular}{|c|c|c|c|c|c|c|}
\hline \multirow{2}{*}{\multicolumn{2}{|c|}{ Model }} & \multicolumn{2}{|c|}{$\begin{array}{l}\text { Un-standardized } \\
\text { Coefficients }\end{array}$} & \multirow{2}{*}{$\begin{array}{l}\text { Standardized } \\
\text { Coefficients } \\
\text { Beta }\end{array}$} & \multirow[t]{2}{*}{$\mathbf{T}$} & \multirow[t]{2}{*}{ Sig. } \\
\hline & & B & Std. Error & & & \\
\hline 1 & (Constant) & .025 & .111 & & .225 & .823 \\
\hline & Work premises $(\mathrm{X} 1)$ & .092 & .025 & 0.157 & 3.664 & .000 \\
\hline & Technological Factors(X2) & .093 & .024 & 0.125 & 3.817 & .000 \\
\hline & Infrastructural Factors(X3) & .079 & .025 & 0.110 & 3.226 & .002 \\
\hline & Marketing Factors(X4) & .388 & .041 & 0.420 & 9.457 & .000 \\
\hline & Financial Factors(X5) & .171 & .037 & 0.203 & 4.641 & .000 \\
\hline & Managerial Factors(X6) & .134 & .031 & 0.156 & 4.325 & .000 \\
\hline & Entrepreneurial Factors $(\mathrm{X} 7)$ & .050 & .022 & 0.107 & 2.253 & .026 \\
\hline
\end{tabular}

Dependent Variable: Performance of MSEs

Source: Own Survey result, 2019

$\mathrm{Y}=0.025+0.092 \mathrm{X} 1+0.093 \mathrm{X} 2+0.079 \mathrm{X} 3+0.388 \mathrm{X} 4+0.171 \mathrm{X} 5+0.134 \mathrm{X} 6+0.050 \mathrm{X} 7$

Multiple Regression analysis result also showed that the Beta weight largest influence on the performance of MSEs is from the marketing factor $(0.420)$, the Financial factor $(0.203)$ and at the third place from Working premises factor (0.0.157), this is the average amount the dependent variable increases when the independent variable increases by one standard deviation (all other independent variables are held constant). The three independent variables are statistically significant since the significance value is less than 0.05 . These results indicate that the variables marketing, finance and working premise make the strongest unique contribution in explaining the dependent variable MSEs performance.

\section{Hypothesis test result}

The hypothesis test results were presented as follows.

Hypothesis 1: Working premises factors

H1: The hypothesis testing of variable Working premises has a positive and significant effect on business performance in Hosanna town; at $p$ value of $\leq 0.05$ and $\beta$ value 0.092 . Therefore, null hypothesis was rejected. The result indicates that working premises factors (Absence of adequate own working premises, inconveniency of current working place, too high rent of working premises is and access to land for business expansion) is significant 
influences between working premises and the business performance. Furthermore, the beta value of 0.092 implies that an increase in the effectiveness of working premises by one unit leads to an increase in business performance by 0.092 . This means that the better the working premises results the better the business performance of MSEs.

\section{Hypothesis 2: Technology factors}

The hypothesis testing of variable technological factors has a positive and significant effect on the business performance in Hosanna Town; at $p$ value of $\leq 5 \%$ and $\beta$ value 0.093 . The value of $p \leq 0.05$ with contribution of $\beta=0.093$ revealed that, Technology has a significant effect on business performance. Therefore, null hypothesis was rejected. The result indicates that a technological factor (Lack of appropriate machinery and equipment, Lack of skills to handle new technology, ability to deploy and use information technology and ability to select proper technology) has a significant influence/effect on the business performance of MSEs in the Town. Moreover, the beta value of 0.092 implies that an increase in the effectiveness of Technology by one unit leads to an increase in business performance by 0.093 . This means that absence of problems of technology leads to the better business performance of MSEs.

\section{Hypothesis 3: Infrastructural factors}

The hypothesis testing of variable Infrastructural factors has a positive and significant effect on the MSEs business performance in Hosanna Town; at $p$ value of $\leq 0.05$ and $\beta$ value 0.079 . The value of $p \leq 0.05$ with contribution of $\beta=0.079$ revealed that, Infrastructural has a significant effect on business performance. Therefore, null hypothesis was rejected. The result indicates that infrastructural factors (Frequent electric power interruptions, Insufficient and interrupted water supply system, Lack of business development services (supporting institutions), Lack of sufficient and quick transportation service and Lack of appropriate dry waste and sewerage system) is significance influences between infrastructure and the business performance. Likewise, the beta value of 0.079 implies that an increase in the effectiveness of infrastructural by one unit leads to an increase in business performance by 0.079 .

This means that the better the presence of infrastructure facilities results the better the business performance of MSEs. A strong infrastructure enhances the competitiveness of an economy and generates a business environment conducive to firm growth and development. Good infrastructure efficiently connects firms to their customers and suppliers, and enables the use of modern production technologies. On the contrary, deficiencies in infrastructure create barriers to productive opportunities and increase costs for all firms, from micro enterprises to large multinational corporations.

\section{Hypothesis 4: Marketing factors}

The hypothesis testing of variable Marketing factors has a positive and significant effect on the MSEs business performance in Hosanna Town; at $p$ value of $\leq 0.05$ and $\beta$ value 0.388 . The value of $p \leq 0.05$ with contribution of $\beta=0.388$ revealed that, Marketing has a significant effect on business performance. Therefore, null hypothesis was rejected. The result indicates that marketing factors (Inadequate market access for my product/service, Lack of marketing strategy, Lack of market information and demand forecasting, Presence of fierce foreign and domestic competition, Lack of promotion to attract potential customers/users and Poor customer relationship and handling) has significance influences on the business performance of MSEs operating in the Town. Similarly, the beta value of 0.388 implies that an increase in the access of Market by one unit leads to an increase in business performance by 0.388 . This means a good market access will result the good business performance (business profit, sales growth, capital growth, operational efficiency and employee loyalty and turnover).

\section{Hypothesis 5: Financial factors}

The hypothesis testing of variable financial factors has a positive and significant effect on the MSEs business performance in Hosanna Town; at $p$ value of $\leq 0.05$ and $\beta$ value 0.171 . The value of $p \leq 0.05$ with contribution of $\beta=0.171$ revealed that, finance has a significant effect on business performance. Therefore, null hypothesis was rejected. Correspondingly, the beta value of 0.171 implies that an increase in the accessibility of Finance by one unit leads to an increase in business performance by 0.171 . That means the easiness to access the finance the better the business performance of the MSEs would be. Finance is one of the key factors that affect the business performance of enterprises. This result supported by the study by the World Bank researchers, Finance is one of the most important functions of any business. Not only is finance a good indicator of the health of the company overall, but it also holds an important role in managing business growth. Whether growth is attributable to a larger market capitalization, and increase employee, a new location, a new product or service offering, or a new demographic, finance is the enabler of such opportunities.

\section{Hypothesis 6: Management factors}

The hypothesis testing of variable management factors has a positive and significant effect on the MSEs business performance in Hosanna Town; at $p$ value of $\leq 0.05$ and $\beta$ value 0.134 . The value of $p \leq 0.05$ with contribution of $\beta=0.134$ revealed that, management has a significant effect on business performance. Therefore, null hypothesis was rejected. Also, the beta value of 0.134 implies that an increase in the effectiveness of Management by one unit leads to an increase in business performance by 0.134 . This means that the lack of clear division of duties and responsibility, Presence of ineffective communication, Presence of poor employee handling, Lack of well trained and experienced employees, and Lack of strategic business planning would result in poor business performance 
(business profit, sales growth, capital growth, operational efficiency and employee loyalty and turnover). In other way, the better the managerial skill will result the good the business performance.

\section{Hypothesis 7: Entrepreneurial factors}

The hypothesis testing of variable entrepreneurial factors has a positive and significant effect on the MSEs business performance in Hosanna Town; at $p$ value of $\leq 0.05$ and $\beta$ value 0.050 . The value of $p \leq 0.05$ with contribution of $\beta=0.050$ revealed that, entrepreneurial has a significant effect on business performance. Therefore, null hypothesis was rejected. The result indicates that Entrepreneurial factors (Lack of motivation and drive, Lack of initiative to take calculated business risk, Lack of persistence and courage to take responsibility for one's failure, Absence of initiative to assess ones strengths and weakness, Lack of entrepreneurship training, Lack of information to exploit business opportunities/ lack of benchmarking) has significance influences/effect on the business performance (business profit, sales growth, capital growth, operational efficiency and employee loyalty and turnover) of MSEs in Hosanna Town. Also, the beta value of 0.050 implies that an increase in the effectiveness of Entrepreneurial by one unit leads to an increase in business performance by 0.050 . This means the better the Entrepreneurial skill will result the better the business performance of MSE. In other word, lack of an Entrepreneurial skill will result poor business performance.

\section{Summary and Conclusion}

Based on the multiple linear regression result;

First, access to market and business performance has a positive correlation. Since those MSEs having sufficient access to market grow faster than those that have no access to sufficient market. This finding points to a shortage of marketing skills \& lack of access to market information as the main factor affecting the performance of those entrepreneurs in the sector.

Second, accesses to finance from formal financial sources and business performance of the MSEs have a positive relationship. Since those MSEs that have access to finance from formal financial sources grow faster than those that have no access to finance. In other word, the finding revealed that the loans awarded for the operation and expansion of micro \& small enterprises were severely limited and, consequently, had had a negative effect on the smooth operation and expansion of the small businesses.

Third, MSEs that were operating at own working premise grow faster than those that operates at rented and at family working premise. Besides, those MSEs that were operating their business at rented working premise shown lower growth rate than those MSEs that were operating their business at their family working premise because the growth rate gap between the MSEs operating at own and family working premise is narrow than the MSEs operating at rented working premise.

Forth, according to survey result, the variable possession of management skill has a positive and statistically significant effect on MSEs business performance. A required level of management skill is a significant criterion if one is to be able to make strategically important business decisions, carry reasonable costs and take calculated risks. Furthermore, a required levels of managerial skill increase operational efficiency, profitability and the success of business operators. However, the results of the survey indicated that the required level of management less skilled, and that they were lacking in the skills and knowledge that are derived from higher formal education can affect the business performance.

Fifth, the correlation between technology and performance considered as weak but a significant positive correlation. Technological factors (lack of appropriate machinery and equipment, lack of skills to handle new technology, ability to deploy and use information technology and ability to select proper technology) were the challenges that had a moderate effect that adversely influences the business performance.

Sixth, access to infrastructure is significant factor for the MSEs business performance since those MSEs having sufficient access to infrastructure grow faster than those that have no access to sufficient infrastructure. Therefore, limited to infrastructure access adversely affects the business performance of micro \& small enterprises.

Seventh, entrepreneurial skills were moderately affecting the business performance of MSEs. entrepreneurial factors (lack of motivation and drive, lack of initiative to take calculated business risk, lack of persistence and courage to take responsibility for one's failure, absence of initiative to assess ones strengths and weakness, lack of entrepreneurship training, lack of information to exploit business opportunities/ lack of benchmarking) were the challenges that had a moderate effect $\&$ that adversely influences the business performance.

Finally the regression model was evaluated for its validity and usefulness to predict the business performance based on the residual plot techniques and the model was found consistent with the multiple linear regression assumptions and found valid and useful to predict the business performance and $90.90 \%$ of the variation was explained by the model.

\section{REFERENCE}

[1] Admasu A. (2012), Factors affecting the performance of micro and small enterprises iArada and Lideta SubCities. A thesis submitted to the school of graduate studies of AddisAbaba University. Addis Ababa. 
[2] Atalele F. (2017), Factors Affecting Business Performance of Small and Medium Size Enterprise (SMEs) in Addis Ababa: (In Case of Nifas Silk-Lafeto Sub-City)

[3] ADB (2010). Determinants of SME startups in Ethiopia: A theoretical exploration Tunis, Tunisia.

[4] Antenane (2017), Factors affecting performance of Micro and Small Enterprises in Addis Ababa: The case of Addis Ketema Sub City Administration (City Government of Addis Ababa)

[5] Ayyagari, M., Ash, D. \& Vojislav, M. (2006). How important are financing constraints? The role of finance in the business environment. World Bank policy research working paper, No.3820.

[6] Chittithawan C., Islam A., Keaw C., Halsiza D., and Yusuf M. (2011).Factors affecting small and medium enterprises business in Thailand.Asian social science, Vol7, No.5, 2011 5, 15-21.

[7] CPMN (1999), Performance measurement audit.http://www.measure.net/audit/index.htm.Accessed on 25 August 2016.

[8] Creswell J. W. (2009): Research Design: Qualitative, Quantitative, and Mixed Methods Approaches, 3rd edition. Landon, Sega publications.

[9] Desta F. (2015) factors affect the growth of micro and small enterprises in Hosanna Town, SNNPR.

[10] Deksiso (2018), Assessment of the factors affecting the performance of micro and small scale enterprise: The case of Wolkite town, Guraghe zone, Southern Ethiopia

[11] Dess,G.\&Robinson, R.(1984). Measuring organizational performance in the absence of objective measures: the case of the privately held firm and conglomerate business unit.Strategic Management Journal. Vol5.

[12] Endalkachew, M. (2008).Underlying causes of micro and small business failures.Addis Ketema Sub City. AddisAbaba.

[13] Federal Micro and Small enterprises Development Agency Establishment council of Ministers (2011).Federal Negarit Gazeta of the federal democratic Republic of Ethiopia. Regulation No. 201/2011, Addis Ababa.

[14] Gebreegziabher, T. \& Demeke, M. (2004). Small businesses in small towns of the eastern Amhara region: Nature and economic performance. A Research report on IDR, Addis AbabaUniversity.

[15] Getachew (2017), Factors Affecting Micro and Small Enterprises in Accessing Credit Facilities: A Study in Hadeya Zone, Hosanna Town Southern Ethiopia

[16] Grigoroudis and Siskos (2010); "Multiple linear regression analysisand beyond.PEARSON Allyn \& Bacon

[17] Haftom, Fessha, and Araya (2014).External Factors Affecting the Growth of Micro and Small Enterprises (MSEs) in Ethiopia: A Case Study in Shire Indasselassie Town, Tigray

[18] Hailemichael M. (2014), assesing the factors affecting the performance of micro and small scale enterprises the case of yeka sub-city,Addis Ababa

[19] Janet(2006), essentials of research methods. A guide to social science research. USA, Blackwell publishing

[20] Kaleleoul F. (2016), Factors Influencing the performance of micro and small enterprises in Addis Ababa: A study of selected MSE in Bole sub city .

[21] Kamunge S. M., Njeru A., and Tirimba I. O. (2014).Factors affecting the Performance of Small and Microenterprise in Limuru town market of Kiambu County,Kenya. International Journal of Scientific andResearch Publications, Volume 4, Issue 12.

[22] Martin Ogutu. (2010). An Investigation into the Effect of Management Factors on Performance of (Micro, Small and Medium Enterprises) in Kenya. International Journal of Business and Management, 5(11):66-73.

[23] Mesfin S. (2015), Challenges and Prospects of Small Enterprises in Ethiopia: A Study of Entrepreneurs in Tigray Region..

[24] Mekonnen L. (2014), Assessing Factors Affecting Transitional Development of Small Scale to Medium Scale Enterprise in Sebeta Town: Challenges, Opportunities and Prospects.

[25] Mugenda, A. G., \&Mugenda, O. M., 2003; Research Methods, Quantitative and Qualitative Approaches, ACTSPress, Nairobi.

[26] Mulugeta chane wube.(2011). Factors affecting the performance of Women Entrepreneurs in Micro and small enterprises (the case of Dessie Town).

[27] OECD (2010). High-Growth Enterprises: What governments can do to make a difference,OECD studies on SMEs and entrepreneurship? OECD publishing.

[28] Pasanen, M. (2007). SME growth strategies: organic or non-organic? Department of business and management, university of Kuopio, Finland.Journal of enterprising culture.vol.15 (317).

[29] Pfeffer, J. \& Salancik, G.(1978). The external control of organization: a resource dependentperspective. New York: Harper and Raw.

[30] Selamaeit N. and Nigus A.(2014). Determinants of Micro and Small Enterprises' Access to Finance in Assela Town.

[31] Tegegne Gebre-Egziabher \& Meheret Ayenew (2010).Micro and Small Enterprises as Vehicles for Poverty Reduction, Employment Creation and Business Development: The Ethiopian Experience. Forum for Social Studies, Research Report No. 6, Addis Ababa, Ethiopia

[32] Workneh Fiseha. (2007). The Constraints of Micro and Small Scale Enterprises in Addressing Employment 
Opportunity: The case of Kolfe Keraneo Sub-city, Addis Ababa. MA Thesis in Regional and Local Development Studies.RLDS, Addis Ababa University.

[33] Yamane, T. (1967).Statistics, an introductory analysis (2nd ed.). New York: Harper and Row.

[34] Zuzana, B. (2012). On determinants of SME start-ups in Ethiopia: A theoretical exploration.African Development Bank, Development Research Department, Tunis, Tunisia.

[35] Zikmand.W.G (2010), Business Research Methods. 5th ed. Harcourt Brace College Publisher: United State of America. 